\title{
Measurement and prediction of emissions of aerosols and gaseous precursors from gas turbine engines (PartEmis): an overview
}

\author{
Christopher William Wilson ${ }^{\mathrm{a}, *}$, Andreas Petzold ${ }^{\mathrm{b}}$, Stephan Nyeki ${ }^{\mathrm{c}}$, \\ Ulrich Schumann ${ }^{\mathrm{b}}$, Reinhard Zellner ${ }^{\mathrm{d}}$ \\ a QinetiQ, Centre for Aerospace Technology, Farnborough/Hamps, GU14 OLX, UK \\ ${ }^{\mathrm{b}}$ Institute of Atmospheric Physics (IPA), German Aerospace Center (DLR-IPA), Oberpfaffenhofen, D-82230 Wessling, Germany \\ ${ }^{\mathrm{c}}$ Laboratory of Atmospheric Chemistry, Paul Scherrer Institute (PSI), CH-5232 Villigen, Switzerland \\ ${ }^{\mathrm{d}}$ Institute of Physical and Theoretical Chemistry, University of Duisburg-Essen, D-45117 Essen, Germany
}

Received 3 February 2003; received in revised form 15 September 2003; accepted 13 October 2003

\begin{abstract}
An overview of the goals and achievements of the European PartEmis project (Measurement and prediction of emissions of aerosols and gaseous precursors from gas turbine engines) is discussed in this paper. PartEmis is focussed on the characterisation and quantification of exhaust emissions from a gas turbine engine. The engine was composed of a combustor and a unit to simulate a 3-shaft turbine section (so-called Hot End Simulator; HES). A comprehensive suite of aerosol, gas and chemi-ion measurements were conducted under different, (i) combustor and HES operating conditions, (ii) fuel sulphur and APA101 fuel additive concentrations. Aspects of volatile particle formation, growth factors of carbonaceous particles and sulphur (IV)/sulphur (VI) formation have been modelled using one- and multidimensional representations of the HES and nearfield plume, respectively. The combustor chosen in PartEmis behaves like a typical aircraft engine combustor with respect to thermodynamic data as well as to gas and particulate emissions, which suggests that the PartEmis database may be applicable to contemporary aircraft engines.
\end{abstract}

(c) 2003 Elsevier SAS. All rights reserved.

Keywords: PartEmis; Gas turbine; Test-rig; Emissions; Turbine modelling; Plume modelling

\section{Introduction}

The possible role of gaseous and particulate emissions from aircraft in the upper troposphere and the lowermost stratosphere is currently a matter of concern [28]. Emitted particles are suspected of altering natural cirrus clouds [39] and to initiate the formation of additional cirrus clouds [5, 26], which in turn may alter the radiation balance of the atmosphere and the Earth's surface. Of special interest are the formation and properties of carbonaceous (black carbon/ organic compounds) and volatile particles (hydrocarbon/ sulphur compounds) [33]. Despite numerous studies to investigate exhaust emissions from gas turbine engines, such as AERONOX [32], AEROTRACE [7], POLINAT [35], SULFUR [34] and CHEMICON [6,38], microphysical and chemical properties as well as the influence of engine

\footnotetext{
* Corresponding author.

E-mail address: c.w.wilson@ sheffield.ac.uk (C.W. Wilson).
}

operating conditions still remain poorly characterised with respect to particulate emissions. However, this kind of data set forms a basic pre-requisite for modelling approaches which investigate the role of aviation aerosols and their effect on the environment.

In order to address these issues, the European PartEmis project (Measurement and prediction of emissions of aerosols and gaseous precursors from gas turbine engines) was conceived. PartEmis aimed to go further than earlier plume studies, by gaining a detailed understanding of the composition and transformation of combustion gases and particles as they pass from the combustor through to the engine exit and hence out into the external plume and aircraft wake. PartEmis focussed on the characterisation and quantification of: (i) particle properties with respect to combustor operating conditions, (ii) particle properties as they progress through the engine turbine stages, (iii) the effect of fuel sulphur content (FSC) and a fuel additive, and (iv) the effect of exhaust emissions of non-methane hydrocarbons and chemi-ions on 
the formation of new particles. The database will be used to improve the capabilities of existing models and for the verification of 1-D, 2-D and CFD (computational fluid dynamics) models.

The test-rig facility comprised a combustor that in technological terms is compatible with ICAO (International Civil Aviation Organisation) emissions standards (CAEP 4). An expansion system (so-called Hot End Simulator; HES) that simulated the thermodynamic processes involved in the expansion of gases in the turbine and nozzle was then added in the second round of experiments. The test-rig was based on standard gas turbine designs, rather than on any single commercial design, in order to encourage the wider application of PartEmis results. An extensive set of state-ofthe-art aerosol, gas and chemi-ion measurements were obtained at QinetiQ (Farnborough, UK) during two campaigns: the PartEmis Combustor (January-February 2001) and HES (March 2002) campaigns. This paper outlines the experi- mental aspects and an overview of preliminary results obtained by project partners during both campaigns. ${ }^{1}$ In addition the nature and preliminary results from accompanying modelling activities are also presented.

\section{Test-rig and combustor operating conditions}

In the section below, brief technical details are given of the combustor and test-rig used during PartEmis, while further details are reported elsewhere [25]. A Trace cannular, transpiration cooled combustor (Fig. 1) was used for tests on QinetiQ's High Pressure Combustion Rig (see Fig. 2). An alternative would have been an annular combustor, how-

\footnotetext{
1 The database was compiled by the DLR, is hosted at Leeds University, and may be accessed by contacting either of the following: andreas.petzold@dlr.de, c.w.wilson@sheffield.ac.uk, martin.plour@dlr.de or m.pourkashanian@leeds.ac.uk.
}

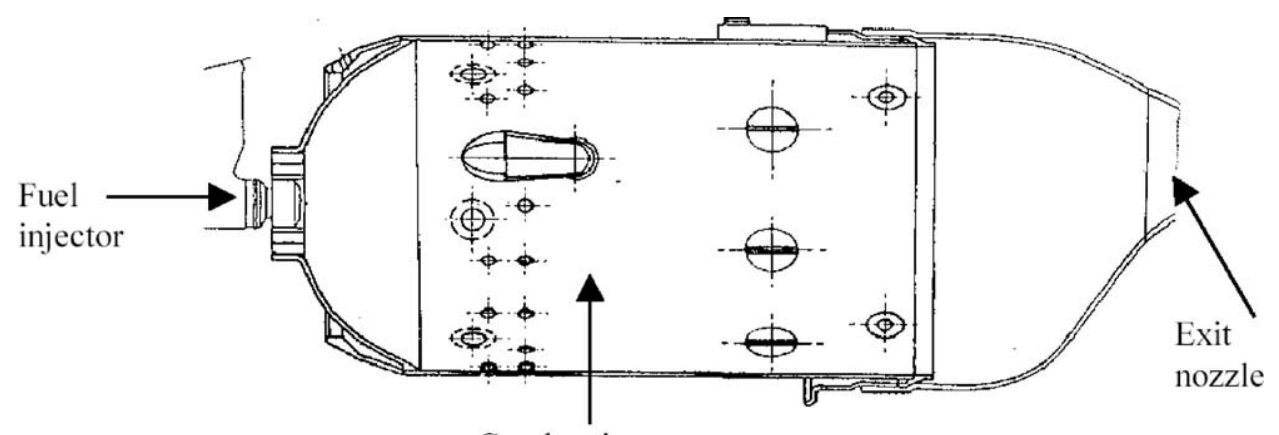

Combustion can

Fig. 1. Schematic of the Trace combustor.

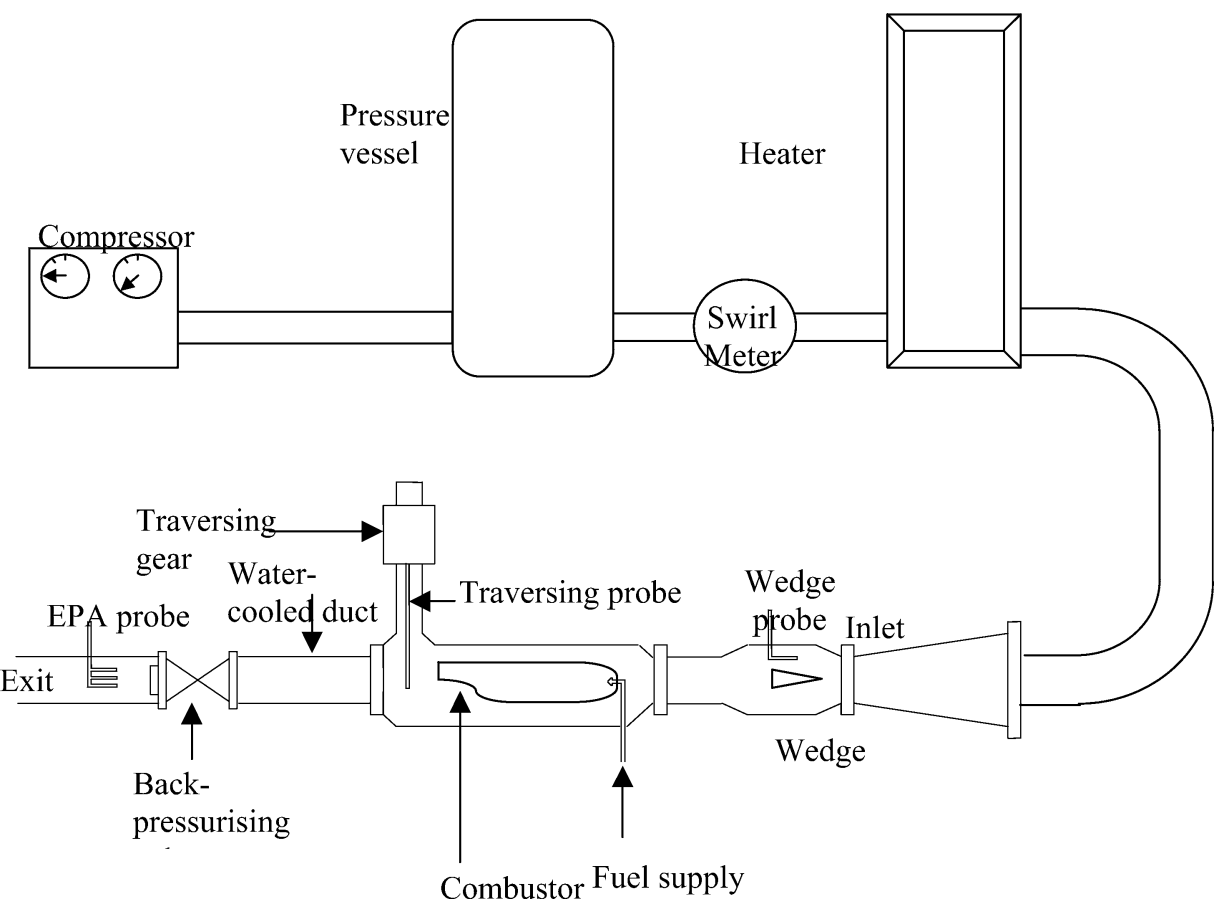

Fig. 2. Schematic of the high pressure combustion test-rig including the combustor. 
ever, this was not chosen for several reasons: (1) A high mass flow would have been required to run a 3-burner sector, and (2) annular combustor sectors have cooled end walls which interfere, normally by reaction quenching, with the combustion products, so the overall combustor exit composition would not be representative of a whole annulus. Although the combustor is based on a 30-year old design, it has been substantially modified with new cooling and fuel injection systems according to current legislation and technological advances such that it meets the emissions requirements of modern civil combustors. The Trace combustor thus provides the best all-round solution. In a working engine, ten of these combustors are circumferentially spaced around the engine core. The combustor exit nozzle used was a $36^{\circ}$ "smile" shaped discharge nozzle, and is shown in Fig. 3. Air was delivered from a four-stage compressor and heater unit. A back-pressurising valve located downstream of the combustor maintained the correct pressure in the system. After extraction of sample exhaust at the combustor exit, the remainder of the high-temperature exhaust gases were cooled using water injection via a set of spray-bars. Watercooled jackets provided additional cooling of pipework. The standard test-rig instrumentation covered 41 control parameters, such as temperature, pressure, fuel and air flowrates, as well as $\mathrm{CO}, \mathrm{CO}_{2}$, total hydrocarbons $(\mathrm{HC}), \mathrm{NO}_{x}$, and smoke number.

Two engine operating conditions, shown in Table 1, were simulated to represent the thermodynamic conditions found in the turbine stages of legacy (referred to here as

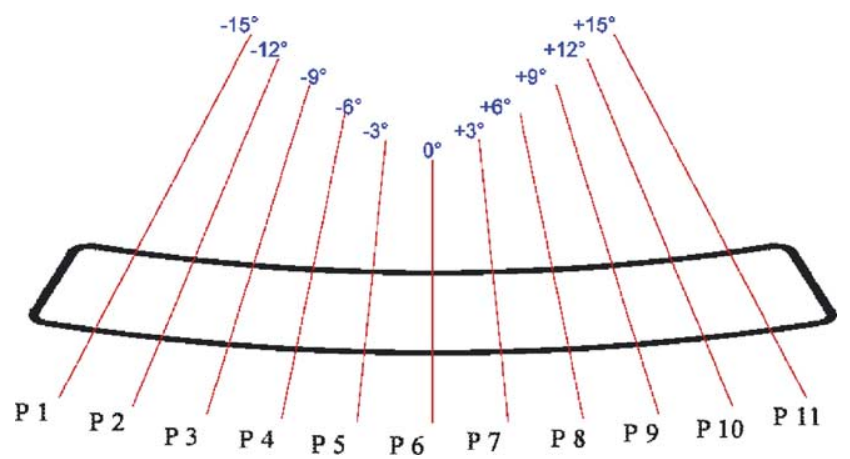

Fig. 3. View of combustor exit looking downstream, illustrating the sampling probe position (P1-11) and angular location. Positions P1 and P11 are close to the combustor walls.

Table 1

Combustor operating conditions during the 2001 Combustor and 2002 HES campaigns

\begin{tabular}{lcccc}
\hline Combustor parameters & \multicolumn{2}{c}{ Combustor campaign } & \multicolumn{2}{c}{ HES campaign } \\
\hline & Old & Modern & Old & Modern \\
\cline { 2 - 5 }$T_{\text {ci combustor inlet }(\mathrm{K})}$ & 566 & 766 & 566 & 766 \\
$T_{\text {co combustor outlet }(\mathrm{K})}$ & 1125 & 1448 & 1125 & 1360 \\
$p_{\text {co }}\left(10^{5} \mathrm{~Pa}\right)$ & 7.05 & 8.2 & 7.05 & 8.2 \\
Air mass flow $\left(\mathrm{kg} \mathrm{s}^{-1}\right)$ & 2.12 & 2.12 & 2.12 & 2.12 \\
Fuel-flow $\left(\mathrm{kg} \mathrm{s}^{-1}\right)$ & 0.032 & 0.042 & 0.032 & 0.035 \\
Air fuel ratio & 66 & 50.3 & 66 & 60.4 \\
\hline
\end{tabular}

"old") and modern aircraft cruise conditions at 35,000 feet ( $\sim 11,700 \mathrm{~m}$ ). This enabled the conversion of fuel sulphur to oxidised sulphur species to be replicated. Due to the large number of test parameters investigated during PartEmis (i.e. combustor operating conditions, FSC, etc.), abbreviations used here and in follow-on papers are shown in Table 2. These old and modern combustor operating conditions were also chosen to meet the ICAO smoke emission level. The base fuel was a low-sulphur kerosene. Amongst other constituents, the aromatic and naphthalene contents were determined to be 18.1 and $2.56 \% \mathrm{v} / \mathrm{v}$, respectively (QinetiQ internal report). The FSC content of this fuel was varied by adding known quantities of benzenethiol $\left(\mathrm{C}_{6} \mathrm{H}_{5} \mathrm{SH}\right)$. FSC levels covered the range from low sulphur fuel $\left(50 \mu \mathrm{g} \mathrm{g}^{-1}\right)$ to the contemporary average $\left(410 \mu \mathrm{g} \mathrm{g}^{-1}\right)$ and to a maximum of about three times this average $\left(1270 \mu \mathrm{gg}^{-1}\right)$ defined here as Low, Mid and High (L, M, H) FSC, respectively. This compares to an upper, allowed limit of $3000 \mu \mathrm{g} \mathrm{g}^{-1}$ according to aviation fuel specifications. In addition, a Shell additive known as APA101 (0, 256, $1280 \mathrm{mg} \mathrm{l}^{-1}$; None, Standard, High or N, S, H) was used with low FSC fuel in order to study the effects on exhaust emissions. This additive was originally developed to extend the thermal stability of JP-8 jet fuel for use in military applications by at least $100^{\circ} \mathrm{F}$ $\left(55^{\circ} \mathrm{C}\right)$. The use of APA101 Additive has been shown to: (i) increase the thermal stability of JP-8, (ii) reduce fuel manifold and nozzle coking deposits in gas turbine engines, and (iii) clean-up carbon deposits in the hot engine sections from the combustor through to the afterburner [15,24]. The direct benefits are reduced fuel-related maintenance costs and increased reliability of turbine engines. APA101 additive fuel has found widespread use in US military aircraft and is currently being assessed by at least one commercial airline. A reduction in particle emission indices (i.e., mass and number) has been observed in various unpublished studies, however, this remains to be further investigated and is an important aspect of PartEmis.

A specially designed equal area traverse-sampling probe was used to extract exhaust samples from the combustor exit, previously shown in Fig. 3. The probe gave a radiallyaveraged value at each circumferential position. The sampling probe was moved stepwise, laterally across the combustor exit (eleven positions), where positions 1 and 11 were close to the combustor walls and position 6 was central. This allowed the lateral distribution of gaseous and aerosol species to be measured. After exit from the traversing probe, the sample was cooled to $\sim 150^{\circ} \mathrm{C}$ using a water-jacket, and delivered to the undiluted and diluted sample lines, shown in Fig. 4. The undiluted line was insulated along its entire length (34 m; tube diameter $7.6 \mathrm{~mm}$ ) in order to avoid wall losses of combustion products, while sample in the diluted line (38 m; tube diameter $21.2 \mathrm{~mm}$ ) naturally attained room temperature $\left(\sim 25^{\circ} \mathrm{C}\right)$ after dilution by a factor $\sim 65$. The respective dilution factor for each test condition varied from 51 to 73 (average 63.4 for entire test series) with a variability of less than $10 \%$, as illustrated in Fig. 5. Dilution with 
Table 2

Definition of test conditions during the 2001 combustor and 2002 HES campaigns

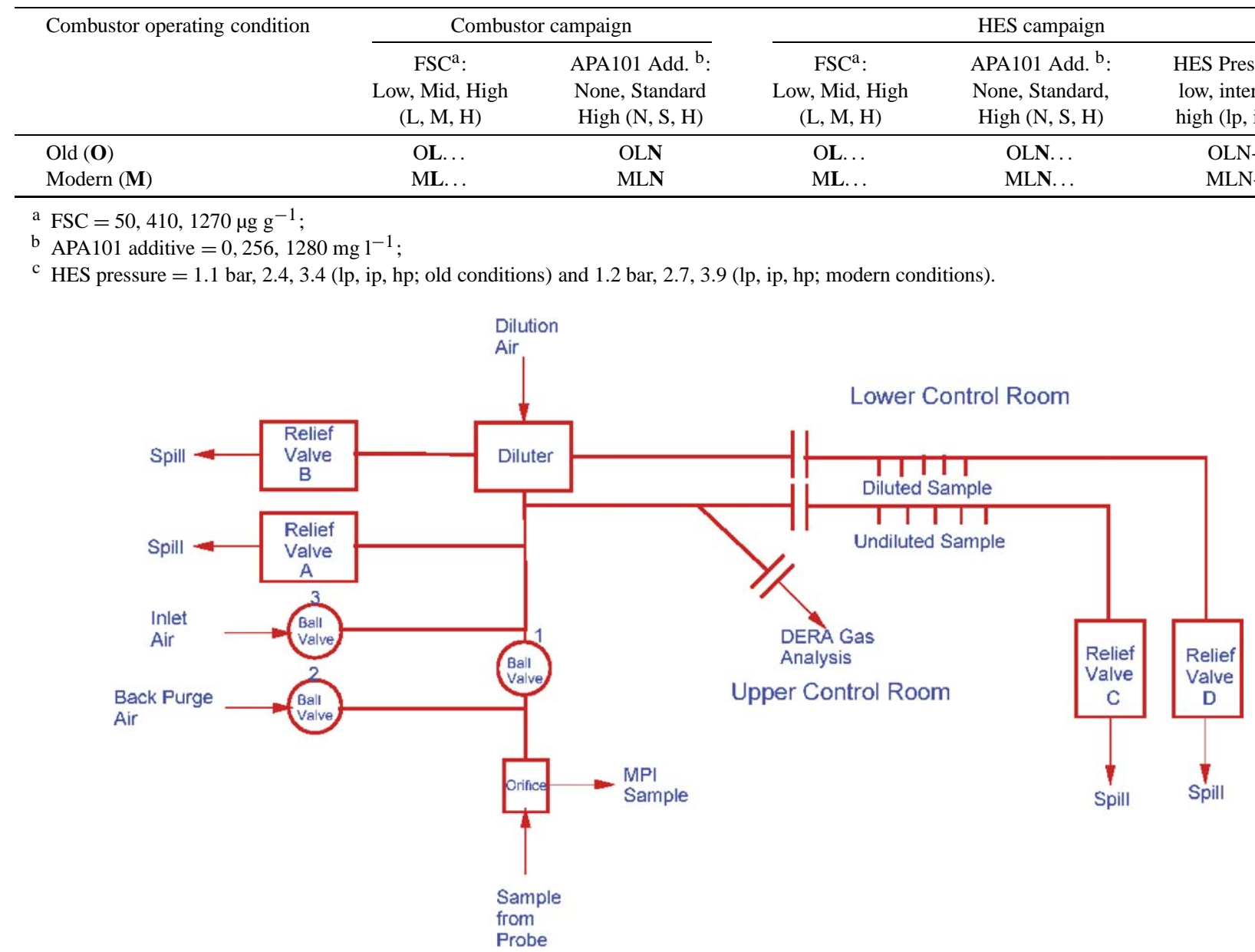

Fig. 4. Diluted and undiluted sampling line system downstream of the combustor exit. The lengths of the diluted and undiluted lines were about 38 and $34 \mathrm{~m}$, respectively. Corresponding tube diameters were 21.2 and $7.6 \mathrm{~mm}$.

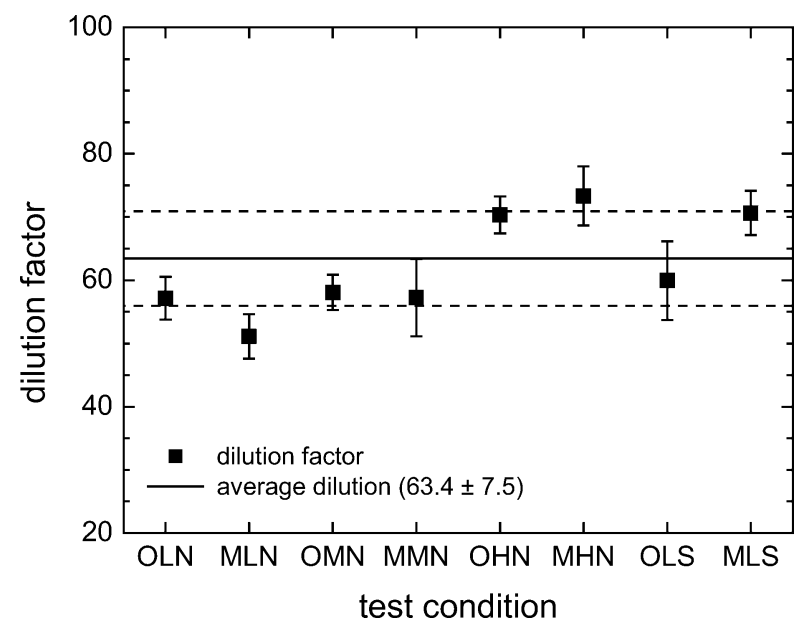

Fig. 5. Average dilution factors for all investigated test conditions. Bars represent the variability of the dilution during the respective test condition, the solid line indicates the average dilution factor, and the dashed lines give the average $+/-1$ the standard deviation of the sample dilution. filtered air was necessary for the majority of instruments to reduce concentrations to a measurable level. The sample dilution factor was determined from $\mathrm{CO}_{2}$ mixing ratios measured in the supplied dilution air, diluted sample, and undiluted sample, as well as from temperature and pressure sensors throughout the sample delivery system. Although stable gaseous species such as $\mathrm{CO}_{2}$ and water vapour are unaffected by intrusive sampling, aerosols may be lost due to diffusion and sedimentation to the surfaces of the sampling system. Aerosol losses were therefore empirically measured and modelled.

\section{Hot end simulator (HES)}

Test-rig turbine systems suffer from mechanical complexity, high costs and testing limitations. As a consequence, it was decided to design a unit with no moving parts, which would simulate variations in gas-stream temperature and pressure in the turbine and propulsion nozzle sections of an engine. Results from the PartEmis Combustor campaign 


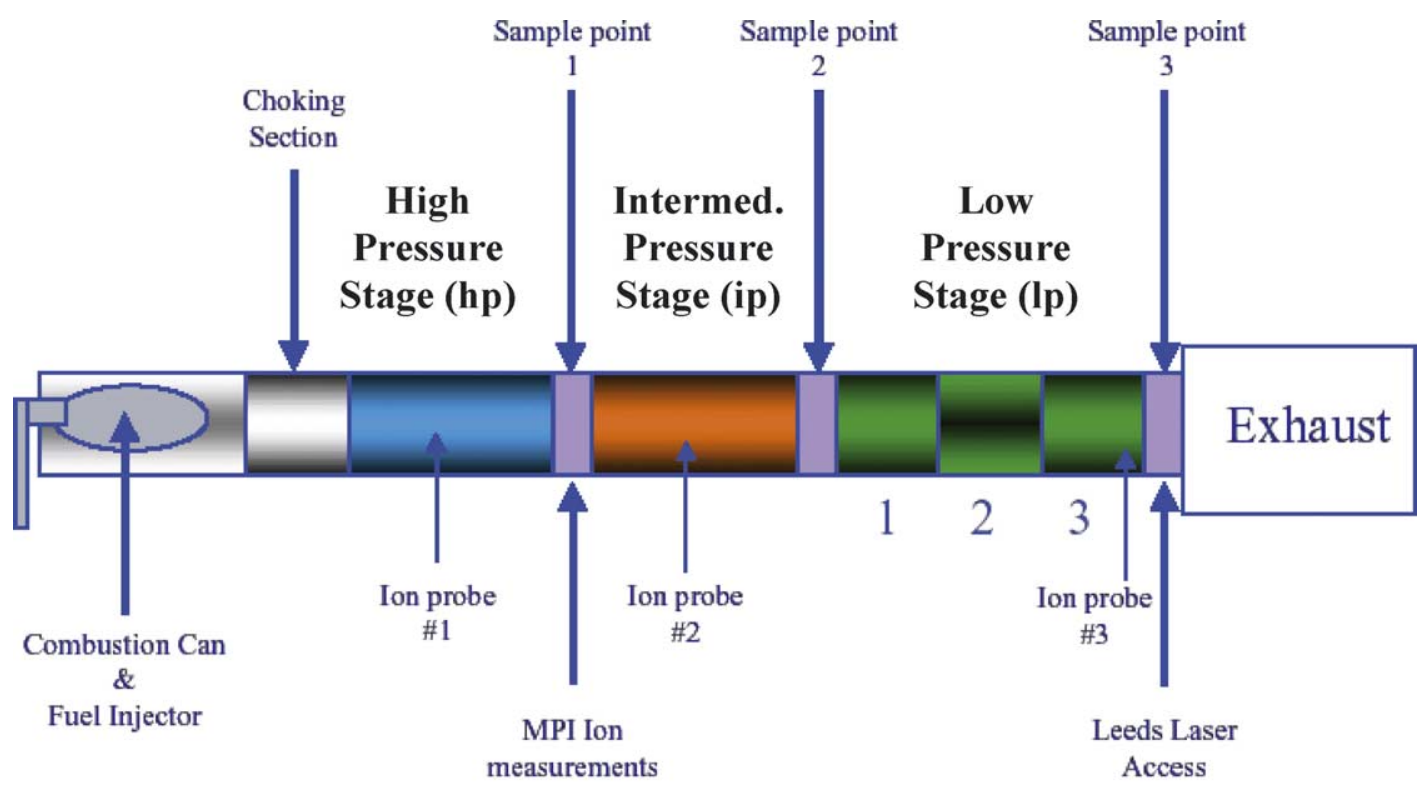

Fig. 6. Schematic of the Hot End Simulator (HES), which is composed of three separate heat exchanger stages (referred to here as the high, intermediate and low pressure stages).

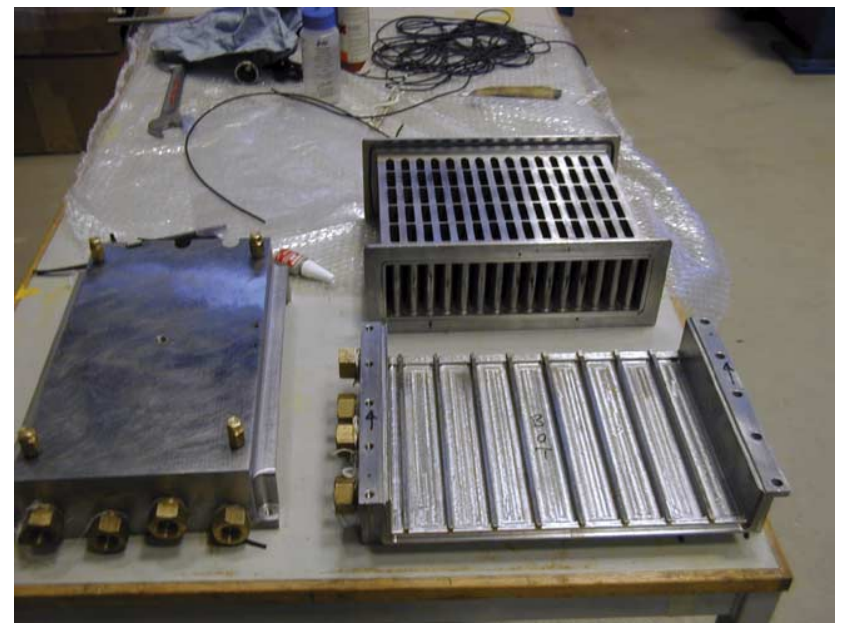

Fig. 7. One of the three heat exchanger stages belonging to the HES. Three such stages compose the HES. Horizontal ducts are for combustion exhaust products and vertical ducts are for water cooling.

provided the boundary conditions for modelling aerosol and aerosol precursor reactions in the HES. A schematic of the HES is shown in Fig. 6, which was designed to have temperature ratios and residence times similar to those found in a modern aircraft engine at a cruise altitude of $35,000 \mathrm{ft}$. The HES was composed of three separate heat exchanger stages, one of which is shown in Fig. 7. Each stage simulated the rotor workload while variation of the cross-sectional area and trimmer plates simulated the pressure stages in a turbine (referred to here as the high, intermediate and low pressure stages; hp, ip, lp). It is not possible to simulate the exhaust pressure at cruise conditions, as this would require a sub-atmospheric facility. However, the pressure loss was attributed to each stage in the same proportion as found in the turbine. The HES does not simulate all of the processes involved. For instance, the HES did not simulate the dynamic effect that a rotating turbine could have on particles. However, it is commonly agreed upon that effects such as turbulent deposition and impaction of particles onto the rotor blade surfaces may have a negligible effect on particle concentrations and will not alter particle physico-chemical properties.

HES test-rig operating conditions during the HES campaign are shown in Table 1. The HES performed within design limits when the combustor was run at cruise conditions. However, it was not possible to achieve modern cruise conditions, as the outlet temperature of the HP heat exchanger exceeded the manufacturers design safety limit of $1125 \mathrm{~K}$. Modern cruise conditions were therefore realised by reducing the fuel-flow until the temperature limit was reached but keeping the inlet temperature, pressure and air mass flow to the combustor at the design values.

An instrumentation section was designed to enable the measurement of gas species concentration and particulate properties at each HES stage exit. The sampling system was essentially the same as that for the Combustor campaign. Individual sample probes for trace gases, aerosols and ions were designed for each measurement section. Selection of sample from the three measurement sections was by remotely operated pneumatic actuated ball valves.

\section{Overview of instrumentation and preliminary experimental results}

A brief overview of the instrumentation operated by each project partner and preliminary results are given in this section. Table 3 contains a list of all instrumental details while 
Table 3

Details of instrumentation and PartEmis experimental partner groups

\begin{tabular}{|c|c|c|c|c|}
\hline Measured parameters & Technique & References & Online/offline & Partner ${ }^{*}$ \\
\hline \multicolumn{5}{|l|}{ Aerosol parameters } \\
\hline $\begin{array}{l}\text { Non-volatile aerosol (total number } \\
\text { conc., number size spectra) }\end{array}$ & $\begin{array}{l}\text { Condensation Nuclei Counters (CNC), Differential Mobil- } \\
\text { ity Analyzer (DMA), Volatility Tandem DMA (VTDMA), } \\
\text { Scanning Mobility Particle Sizer (SMPS) }\end{array}$ & {$[27,30]$} & On & $\begin{array}{l}\text { DLR-IPA } \\
\text { PSI RR }\end{array}$ \\
\hline $\begin{array}{l}\text { Volatile aerosol (total number } \\
\text { conc., number size spectra) }\end{array}$ & CNCs, DMA, VTDMA, SMPS & {$[27,30]$} & On & $\begin{array}{l}\text { DLR-IPA } \\
\text { PSI }\end{array}$ \\
\hline Aerosol surface area conc. & Diffusion Charger (DC) & {$[2]$} & On & PSI \\
\hline Integral optical properties & Aerosol Absorption Photometer & [4] & On & DLR-IPA \\
\hline Aerosol extinction $\sigma_{\text {ext }}$ & Extinction measurement technique & {$[25]$} & On & QinetiQ \\
\hline Smoke number & Smoke number (SN) method & {$[31]$} & On & QinetiQ \\
\hline $\begin{array}{l}\text { Hygroscopic growth factor, } \mathrm{RH} \leqslant \\
95 \%\end{array}$ & Hygroscopicity Tandem DMA (HTDMA) & {$[12]$} & On & PSI \\
\hline $\begin{array}{l}\text { Cloud condensation nuclei super- } \\
\text { saturation } S>0.02\end{array}$ & Thermal gradient $\mathrm{CCN}$ counter & [17] & On & UNIV \\
\hline Chemical composition & $\begin{array}{l}\text { Berner low pressure impactor, gravimetry (total mass), } \\
\text { thermal method (organic/elemental carbon), thin layer } \\
\text { chromatography (aliphatic, aromatic, polar constituents), } \\
\text { ion chromatography (major ions), atomic absorption spec- } \\
\text { troscopy (trace metals) }\end{array}$ & [16] & Off & TUV \\
\hline \multicolumn{5}{|l|}{ Gas parameters } \\
\hline $\mathrm{CO}, \mathrm{CO}_{2}, \mathrm{HC}, \mathrm{SO}_{2}, \mathrm{NO}_{x}, \mathrm{O}_{2}, \mathrm{H}_{2}$ & Standard test-rig instrumentation & {$[25]$} & On & QinetiQ \\
\hline $\mathrm{H}_{2} \mathrm{SO}_{4}, \mathrm{SO}_{3}$ & Chemical ionisation mass spec. (CIMS) & {$[18]$} & On & MPI-K \\
\hline Gaseous Ions & Ion mobility analyser (IMA) & [14] & On & MPI-K \\
\hline Charged soot particles & $\begin{array}{l}\text { Ion mobility analyser (IMA) and large ions mass spec- } \\
\text { trometer (LIOMAS) }\end{array}$ & {$[1]$} & On & MPI-K \\
\hline \multirow[t]{2}{*}{ NMVOCs $\left(\mathrm{C}_{2}-\mathrm{C}_{10}\right)$} & Quasi-on-line gas chromatography (GC); Off-line GC- & {$[23]$} & On & BUGHW \\
\hline & MS-FID & & Off & BUGHW \\
\hline $\begin{array}{l}\text { Partially oxidised hydrocarbons. } \\
\text { Carbonyl compounds, organic acids }\end{array}$ & $\begin{array}{l}\text { Carbonyls: DNPH (2,4-dinitrophenyl-hydrazine); Organic } \\
\text { acids: } \mathrm{K}_{2} \mathrm{CO}_{3} \text { cartridges; Off-line HPLC analysis }\end{array}$ & [13] & Off & DLR-VT \\
\hline $\mathrm{OH}$ & Laser-induced fluorescence (LIF) & [42] & On & U. Leeds \\
\hline
\end{tabular}

* Institute abbreviations: QinetiQ (QinetiQ, Centre for Aerospace Technology, Farnborough, England), DLR-IPA (Institute for Atmospheric Physics, German Aerospace Centre, Oberpfaffenhoffen, Germany), PSI (Lab. Atmospheric Chemistry, Paul Scherrer Institute, Switzerland), RR (Rolls Royce, Derby, England), UNIV (Institute for Experimental Physics, Univ. Vienna, Vienna, Austria), TUV (Institute for Analytical Chemistry, Technical Univ. Vienna, Vienna, Austria), MPI-K (Atmospheric Physics Dept., Max Planck Institute, Heidelberg, Germany), BUGHW (Bergische Univ. Wuppertal, Germany), DLR-VT (Institute of Combustion Technology, Germany Aerospace Centre, Stuttgart, Germany), U. Leeds (Dep. Chemistry, Univ. Leeds, Leeds, England).

Table 4

PartEmis Combustor campaign: Details of test schedule

\begin{tabular}{lcccc}
\hline Date & $\begin{array}{c}\text { Combustor } \\
\text { condition }\end{array}$ & $\begin{array}{c}\text { FSC } \\
\left(\mu \mathrm{g} \mathrm{g}^{-1}\right)\end{array}$ & $\begin{array}{c}\text { APA101 Add. } \\
\left(\mathrm{mg} \mathrm{l}^{-1}\right)\end{array}$ & Notation \\
\hline 25 January 2001 & Old & 50 & None & OLN \\
& Modern & 50 & None & MLN \\
26 January 2001 & Old & 410 & None & OMN \\
& Modern & 410 & None & MMN \\
29 January 2001 & Old & 1270 & None & OHN \\
& Modern & 1270 & None & MHN \\
31 January 2001 & Old & 50 & 256 & OLS \\
& Modern & 50 & 256 & MLS \\
1 February 2001 & Old & - & - & - \\
& Modern & 50 & 1280 & MLH \\
\hline
\end{tabular}

* Sampling time per test point $\sim 180$ mins.

the various test conditions during the PartEmis Combustor and HES campaigns are detailed in Tables 4 and 5, respectively. As already mentioned, exhaust emissions were measured for aerosol, gas and chemi-ion properties. Basic aerosol properties measured included the following [27,30]: the number and mass concentrations, size distribution, mix- ing state, and volatile fraction of internally mixed particles. The combustor operating conditions were found to have a weak influence on the size, number and mass of emitted particles. Increasing the FSC slightly increased the total number of emitted particles. At high FSC levels the formation of new particles with diameters $d<10 \mathrm{~nm}$ by homogeneous nucleation was observed. Particles of size $d \geqslant 30 \mathrm{~nm}$ were almost entirely internally mixed. Smaller particles $(d<20 \mathrm{~nm})$ exhibited volume fractions of $10-15 \%$ and $4-10 \%$ for volatile and semi-volatile material, respectively, while the volatile fraction decreased to $<5 \%$ for $d \geqslant 50 \mathrm{~nm}$ particles.

Particle hygroscopic properties were measured at ambient conditions using a Hygroscopicity Tandem Differential Mobility Analyser (H-TDMA) system [12]. The instrument measures the hygroscopic growth factor $(g)$ of particles with initial dry sizes $d_{0}=30,50$ and $100 \mathrm{~nm}$ over the range $\mathrm{RH} \sim 70-95 \%$ where $g(\mathrm{RH})=d(\mathrm{RH}) / d_{0}$. Growth factors were found to increase with increasing FSC at fixed particle size (e.g. $d_{0}=50 \mathrm{~nm} ; g(95 \%)=1.01$ and 1.16 for $\mathrm{FSC}=$ low and high, respectively). Growth factors also decreased with increasing particle size at fixed FSC (e.g. mid FSC; $g(95 \%)=1.14,1.10$ and 1.03 for $d_{0}=30,50$ and 
Table 5

PartEmis HES campaign: Details of test schedule

\begin{tabular}{|c|c|c|c|c|c|}
\hline Date & Combustor condition & $\mathrm{FSC}\left(\mu \mathrm{g} \mathrm{g}^{-1}\right)$ & APA101 Add. $\left(\mathrm{mg} \mathrm{l}^{-1}\right)$ & HES pressure stage & Notation $^{*}$ \\
\hline \multirow[t]{2}{*}{15 March 2002} & Old & 50 & 299 & hp, ip, lp & OLS-hp, ... \\
\hline & Modern & 50 & 299 & hp, ip, lp & MLS-hp, ... \\
\hline \multirow[t]{2}{*}{17 March 2002} & Old & 50 & 1430 & hp, ip, lp & OLH-hp, ... \\
\hline & Modern & 50 & 1463 & hp, ip, lp & MLH-hp, ... \\
\hline \multirow[t]{2}{*}{18 March 2002} & Old & 50 & None & hp, ip, lp & OLN-hp, ... \\
\hline & Modern & 50 & None & hp, ip, lp & MLN-hp, ... \\
\hline \multirow[t]{2}{*}{20 March 2002} & Old & 400 & None & hp, ip, lp & OMN-hp, ... \\
\hline & Modern & 400 & None & hp, ip, lp & MMN-hp, ... \\
\hline \multirow[t]{2}{*}{21 March 2002} & Old & 1300 & None & hp, ip, lp & OMN-hp, ... \\
\hline & Modern & 1300 & None & hp, ip, lp & MMN-hp, ... \\
\hline
\end{tabular}

* Sampling time per test point; OLS-hp $=20 \mathrm{mins}, \mathrm{OLS}-\mathrm{ip}=22 \mathrm{mins}$, OLS-lp $=40 \mathrm{mins}$, etc.

$100 \mathrm{~nm}$, respectively) [12]. These results suggest an increasing amount of sulphuric acid adsorbed on combustion particles from the gas phase with increasing FSC, which leads to a relatively larger fraction on smaller particles.

Cloud condensation nuclei (CCN) were measured in the diluted line using a static thermal diffusion type $\mathrm{CCN}$ counter [8]. Particles are exposed to controlled supersaturations of water vapour, which enables some of the particles to become activated and grow to large $(>10 \mu \mathrm{m})$ droplets. During PartEmis, the supersaturation was set to $\sim 0.7 \%$. The fraction of $\mathrm{CCN}$ in the aerosol (relative to the concentration of particles $>10 \mathrm{~nm}$ ) increased with increasing FSC, but even for low FSC the fraction of CCN (at $0.755 \%$ supersaturation) was higher than the fraction of particles with diameters larger than $0.280 \mu \mathrm{m}$, i.e. the size at which wettable insoluble particles are activated according to the Kelvin effect. At high FSC, the fraction of CCN increased by about a factor 5.5 for old and 12 for modern conditions but was still lower by a factor $\sim 15$ for those particles with $d>0.03$ $\mu \mathrm{m}$, i.e. the dry size at which sulphuric acid particles would be activated according to Köhler theory. Further details are given elsewhere [17]. Aerosol samples were collected with filter pack samplers and low pressure Berner impactors for total aerosol and size-resolved chemical mass analysis. Impactor foils and teflon filters were analysed for mass concentration, total, organic and elemental carbon, water soluble ions and extractable organic compounds using a variety of techniques such as: ion chromatography, thermal combustion, gas chromatography, and atomic absorption spectroscopy, respectively. Measurements indicate that the mass mode concentration was in the range $d=60-120 \mathrm{~nm}$ and showed little variation with FSC or combustor conditions.

Non-methane volatile organic compounds (NMVOCs) were monitored using a compact GC instrument (Airmovoc 2010) with an enrichment system (cryotrap) and FID detector $[21,23] . \mathrm{C}_{2}-\mathrm{C}_{10}$ aliphatic and aromatic hydrocarbons (HCs) were measured with a time resolution of $20 \mathrm{~min}$ and detection limits in the pptv range. More than 90 different aliphatic and aromatic HCs were identified and quantified: these species accounted for up to $91 \mathrm{wt} \%$ of the total detectable compounds. A decrease in $\mathrm{HC}$ emissions with increasing combustor power at the same FSC was found. No clear influence on the $\mathrm{HC}$ emissions with changing FSC at the same combustor power was observed. The calculated emission indices ( $\mathrm{mg} / \mathrm{kg}$ fuel) were found to be in agreement with results from the AEROTRACE study [22].

Partially oxidised hydrocarbons such as aldehydes and organic acids were collected in special sampling cartridges and measured off-line using HPLC with a photo-array detector. Emission indices ( $\mathrm{mg} / \mathrm{kg}$ fuel) of carbonyl compounds were found to be similar to AEROTRACE tests. The lowest carbonyl emissions were observed for low FSC during the HES campaign. Emission indices of organic acids were about 10 times higher than for carbonyl compounds.

A comprehensive suite of trace gas concentrations and test-rig measurements was conducted by QinetiQ. Trace gas measurements were: $\mathrm{O}_{2}, \mathrm{CO}, \mathrm{HC}, \mathrm{SO}_{2}, \mathrm{NO}, \mathrm{NO}_{x}$, and in particular, $\mathrm{CO}_{2}$ at various points in the dilution system. Other parameters such as $\mathrm{NO}_{2}, \mathrm{~N}_{2}, \mathrm{H}_{2} \mathrm{O}$ were calculated from these measurements. Standard online thermodynamic and test-rig parameters included: temperature and pressure at numerous locations throughout the system, combustor efficiency, air-to-fuel ratio (AFR), emission indices, smoke number.

Gaseous sulphuric acid was measured using a CIMS (Chemical Ionisation Mass Spectrometer) apparatus equipped with an Ion Trap Mass Spectrometer (ITMS). The ITMS allows CID (Collision-Induced-Dissociation) investigations of mass selected ions to be performed which in turn allows much better species identification than can be offered by a conventional mass spectrometer. In order to avoid sampling line losses a relatively short sampling line $(200 \mathrm{~cm})$ without dilution and with a temperature exceeding $150^{\circ} \mathrm{C}$ was used. Total gaseous $\mathrm{S}(\mathrm{VI})\left(\mathrm{SO}_{3}\right.$ and $\left.\mathrm{H}_{2} \mathrm{SO}_{4}\right)$ concentrations increase with FSC and fuel-flow reaching up to $450 \mathrm{ppb}$ at the low pressure stage of the HES in the modern cruise condition for high FSC. The conversion efficiency $\varepsilon=\mathrm{S}(\mathrm{VI}) / S_{T}$ (where $S_{T}=$ total sulphur) was determined using the measured FSC. The parameter $\varepsilon$ increases with increasing exhaust age in the HES and increasing fuel flow. It is $1.3 \pm 0.7 \%$ at the combustor exit and up to $2.3 \pm 1.2 \%$ at the low pressure stage for the modern cruise condition for $\mathrm{FSC}=1270 \mathrm{ppm}[18]$. 
Gaseous ions were measured during the HES Campaign using an ion mobility analyzer (IMA). The IMA was not equipped with a sampling line (in order to avoid ion losses) but was attached directly to the HES at the high pressure stage (sample point 1 in Fig. 6). Both concentrations of positive and negative ions were measured, and were observed to increase with fuel-flow to values as high as $1.5 \times 10^{8} \mathrm{~cm}^{-3}$ (negative ions) and $1.2 \times 10^{8} \mathrm{~cm}^{-3}$ (positive ions). Positive and negative gaseous ions with mass numbers up to 1500 were detected for the first time in the internal flow of the aircraft gas turbine engine. The total ion emission index $E_{i}$ of positive and negative ions with respect to burnt fuel attained a value $1.6 \times 10^{16} \mathrm{~kg}^{-1}$. This value is sufficiently high to explain the formation of the numerous volatile aerosol particles observed in the wake of in-flight jet aircraft [14]. Electrically charged soot particles were measured using the IMA and a large ion mass spectrometer (LIOMAS). Both positively and negatively charged soot particles had approximate mass numbers exceeding $5 \times$ $10^{4}[1]$.

$\mathrm{OH}$ laser induced fluorescence (LIF) measurements were performed in the exhaust duct of the HES. The experiment comprised a $\mathrm{Nd} / \mathrm{YAG}$ pumped dye laser set up to generate light at $\lambda=281.913 \mathrm{~nm}$ in order to excite the $\mathrm{Q}_{1}(1)$ transition of $\mathrm{OH} \mathrm{A} \mathrm{A}^{2} \sum\left(v^{\prime}=1\right) \leftarrow X^{2} \prod\left(v^{\prime \prime}=0\right)$, chosen as it is one of the strongest transitions at the temperature expected at the observation point. Fluorescence was detected perpendicular to the path of the laser from the $v^{\prime}=0 \rightarrow$ $v^{\prime \prime}=0$ transition around $309 \mathrm{~nm}$ via a lens and a customised interference filter. In order to maximise the signal to noise ratio by discriminating against Raman scatter expected from nitrogen and water around 302 and $315 \mathrm{~nm}$, respectively, the interference filter was centred at $308.75 \mathrm{~nm}$ with a band pass of $4.96 \mathrm{~nm}$ (FWHM) and $>50 \%$ transmittance in the band pass region. Calibration experiments were performed with a methane/air flame of known composition and measured temperature profile in a McKenna burner. This has been modelled with the PREMIX [19] module of CHEMKIN [20] to simulate a burner stabilised 1-D flame in order to provide the concentration vs. height profile of $\mathrm{OH}$ above the burner surface. After calibrating for the effect of different CCD camera gain and exposure times, accounting for the different Boltzmann population distributions over the $\mathrm{OH}$ ground state, and different quenching rates from the $\mathrm{OH}$ excited state, a preliminary estimate was obtained for the absolute $\mathrm{OH}$ concentration in the HES exhaust duct of $\sim 2 \times 10^{10}$ molecules $\mathrm{cm}^{-3}$ (1.2 ppbv).

\section{HES and plume modelling}

In order to improve detailed understanding of processes leading to particle formation and their precursors as well as to enhance the predictive capability of how these processes depend on turbine operation conditions and FSC, a number of modelling activities were performed in PartEmis. These activities focussed on modelling physical parameters (e.g. pressure and temperature) and selected trace gas concentrations using 1-D and 3-D approaches for both the HES and near-field plume.

The HES 1-D model, developed by Qinetiq (Clague et al., in preparation) is based on the CHEMKIN III software package to describe the time-dependent behaviour of a series of coupled perfectly stirred reactors (PSRs). The major advantage of assuming perfect mixing is that the resulting reduction in complexity is much less demanding in terms of computational time. As a result, it is possible to describe the chemistry using a highly detailed reaction mechanism. Literature searches were employed to ensure the inclusion of all reactions and species believed of relevance in the temperature and pressure regime valid for the HES. The final, full mechanism contained 96 species and 725 reversible reactions, which together describe the gas-phase oxidation of compounds containing up to two carbon atoms as well as the production and destruction of $\mathrm{NO}_{x}$ and $\mathrm{SO}_{x}$ species. The kinetic and mechanistic details were taken from evaluated databases, updated and further developed for $\mathrm{SO}_{x}$ chemistry.

The HES model was initialised using the actual concentrations of the principal bulk combustor products, $\mathrm{CO}_{2}, \mathrm{O}_{2}$, $\mathrm{H}_{2} \mathrm{O}$, CO, unburned hydrocarbons, $\mathrm{NO}$ and $\mathrm{NO}_{2}$, as obtained from the PartEmis combustor database. A number of significant species, such as $\mathrm{OH}$ and $\mathrm{O}$ which could not be measured during the tests but were considered important to the conversion of $\mathrm{SO}_{2}$ to $\mathrm{SO}_{3}$ and $\mathrm{H}_{2} \mathrm{SO}_{4}$ were derived from a chemical model of the combustion system.

Of principal interest to the HES modelling work were the changes of aerosol precursor species as well as the radicals that drive their oxidation. These changes are presented graphically for the sulphur species $\mathrm{SO}_{2}, \mathrm{SO}_{3}$ and $\mathrm{H}_{2} \mathrm{SO}_{4}$ as well as for $\mathrm{O}$ and $\mathrm{OH}$ in Fig. 8(a) and (b) for old and modern cruise conditions, respectively. As can be seen from this figure there is a continuous decay in both $\mathrm{O}$ and $\mathrm{OH}$ through the HES as the species contribute to the oxidation of $\mathrm{CO}, \mathrm{SO}_{2}$ and $\mathrm{NO}_{x}$. Moreover, the figure also shows a clear increase in sulphuric acid, which for both conditions occurs almost exclusively in the HES itself and not in the ducting before and after it. The conversion efficiency $\varepsilon$ of $\mathrm{S}(\mathrm{IV})$ to $\mathrm{S}(\mathrm{VI})$ is calculated to be $0.61 \%$ and $0.57 \%$ for modern and old cruise conditions, respectively, and is almost independent of FSC.

Compared to the overall sulphur conversion efficiency, including both combustor and HES which is calculated to be about $2.1 \%$, the contribution of the HES must therefore be considered as minor. A comparison of the measured and modelled sulphur conversion efficiency shows good agreement for modern cruise conditions but is less satisfactory for old cruise conditions.

Computational Fluid Dynamics (CFD) modelling has provided much greater insight concerning changes of pressure and temperature in the HES than was previously available. Using the Eddy-dissipation turbulence/chemistry inter- 


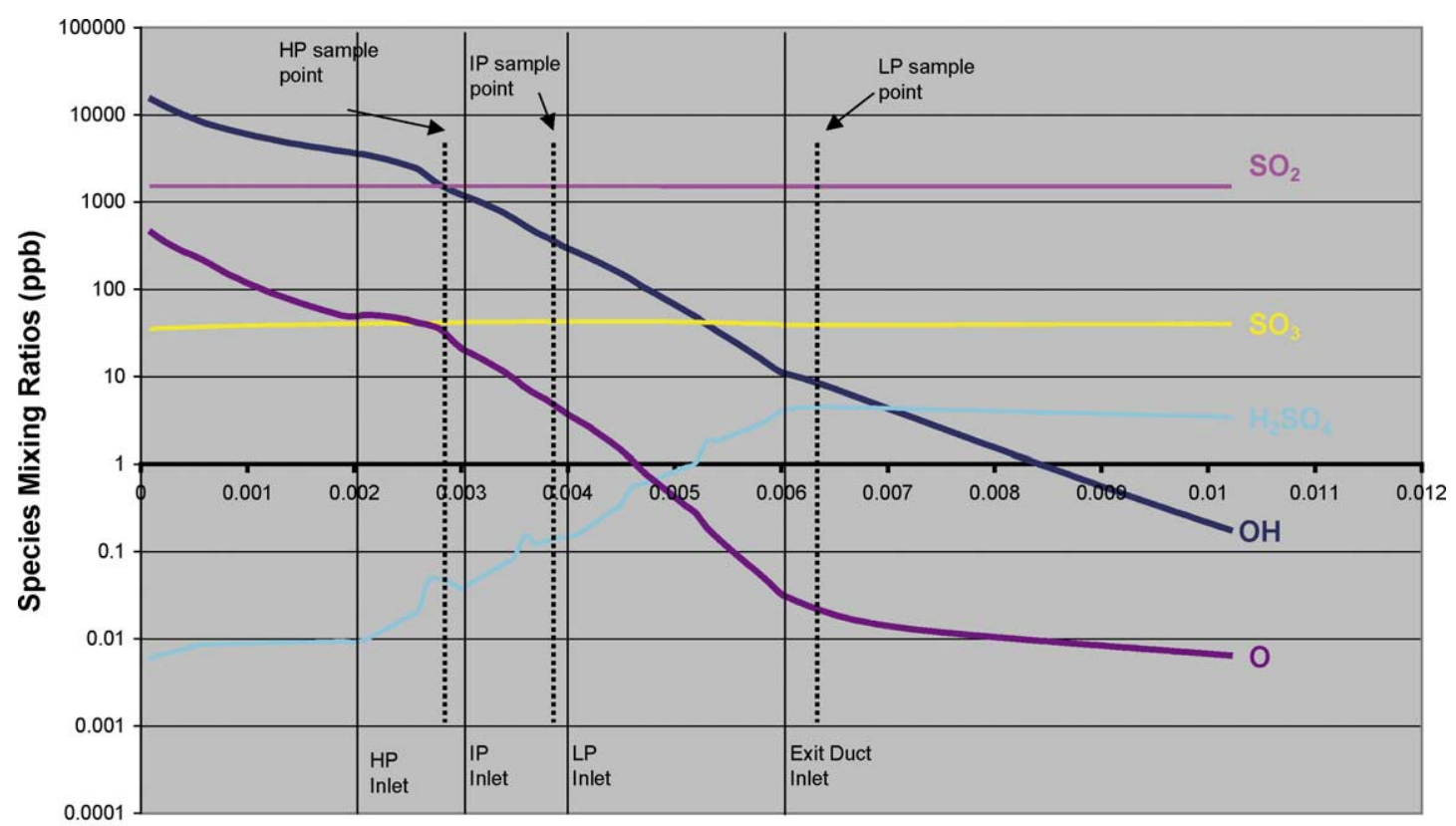

Time (s)

(a)

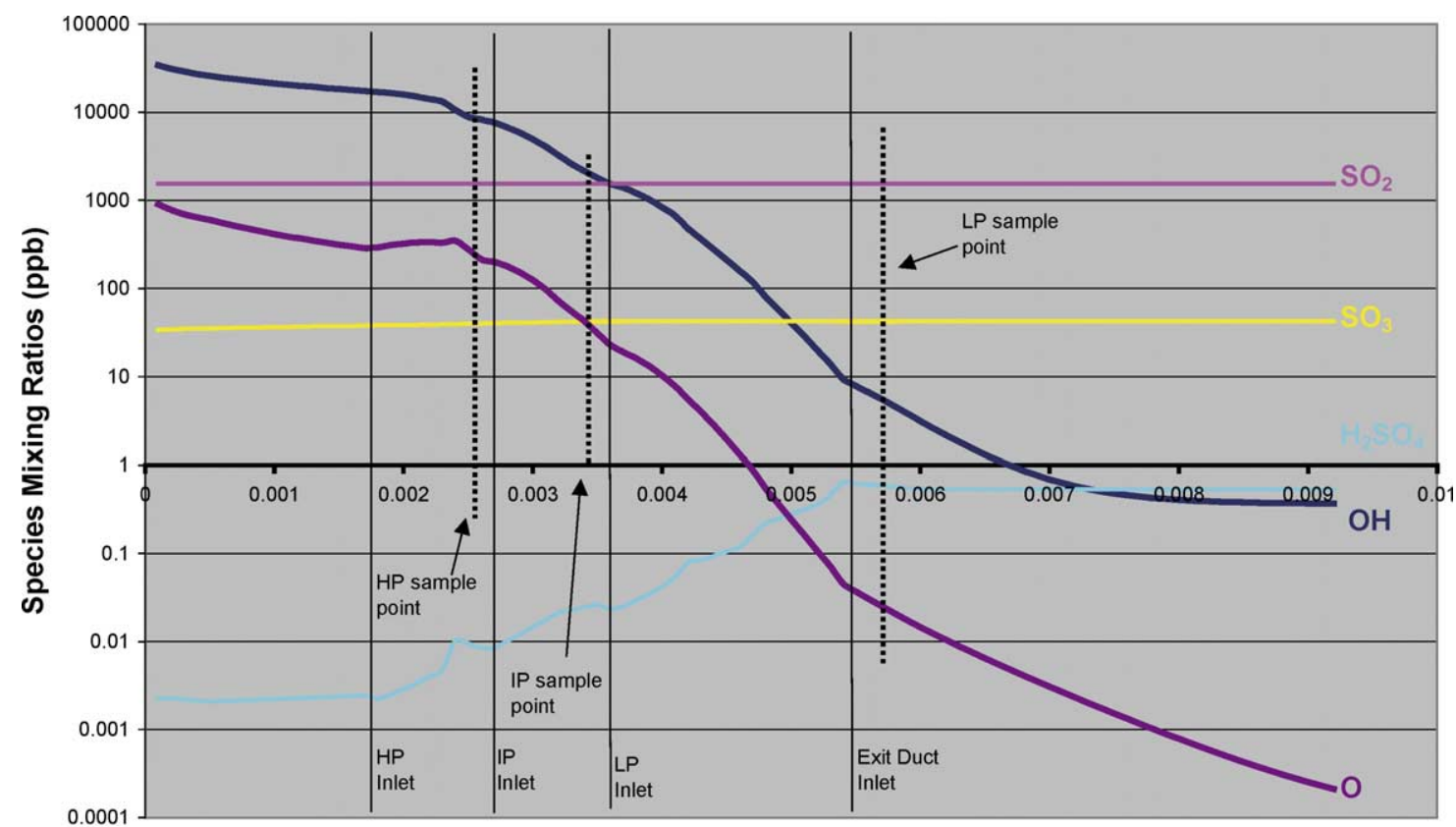

Time (s)

(b)

Fig. 8. Mixing ratio vs. time through the Hot End Simulator (1-D model) for old (top) and modern (bottom) cruise.

action model the evolution and concentration of $\mathrm{SO}_{x}$ species may be predicted. Again the results were found to be in satisfactory agreement with experiment.

Modelling of the jet regime of an aircraft plume was performed using a 3-D chemical-dynamics code developed previously [10,11]. Modelling focussed on the temporal evolution of the major $\mathrm{HO}_{x}, \mathrm{NO}_{x}$ and $\mathrm{SO}_{x}$ species using kinetic and mechanistic data optimised for temperatures below $700 \mathrm{~K}$ as appropriate for the expanding and cooling plume within a distance of approximately $100 \mathrm{~m}$ behind the aircraft. Chemical initialisation of this model was made using both old engine core data [3] and those from PartEmis HES measurements and/or models.

As part of modelling activities a quantum-chemical dynamical calculation [36] of the rate coefficient for the reaction $\mathrm{OH}+\mathrm{SO}_{2}+\mathrm{M} \rightarrow \mathrm{HOSO}_{2}+\mathrm{M}$ was also performed 


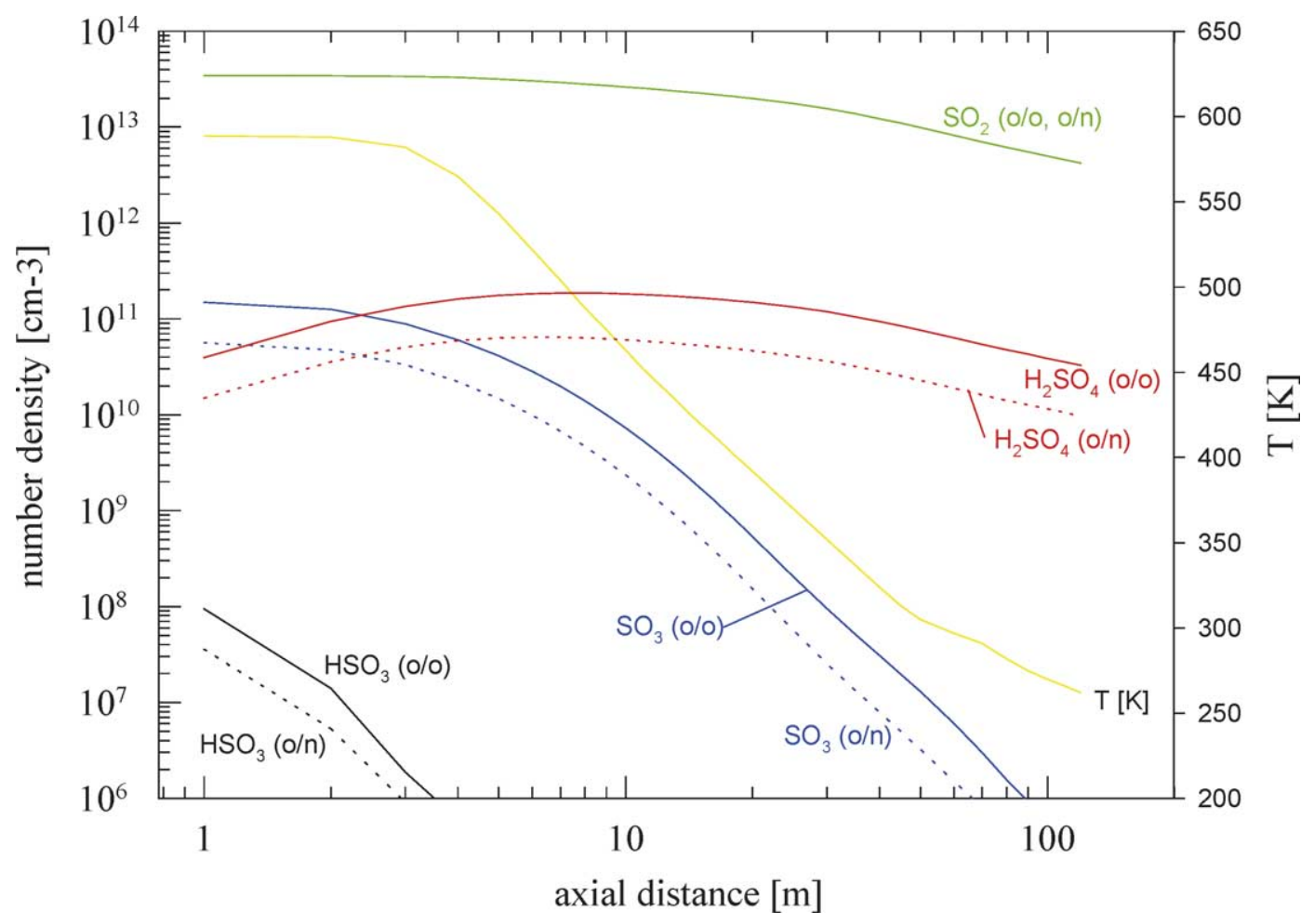

Fig. 9. Evolution of $\mathrm{SO}_{x}$ species for different $\mathrm{HSO}_{3}$ kinetics in the jet regime of a plume (so-called BOAT code). The first symbol "o" represents old combustor conditions, and the second symbol represents either an old "o" or new "n" model run.

which is the rate determining step in the overall oxidation of $\mathrm{S}(\mathrm{IV})$ to $\mathrm{S}(\mathrm{VI})$ at all temperatures below $700 \mathrm{~K}$, i.e. applicable to plume conditions. The results from this work indicate that this recombination process may be considerably slower than previously thought [40]. When included in the plume model chemical code the results suggest that the conversion efficiency of $\mathrm{S}(\mathrm{IV})$ to $\mathrm{S}(\mathrm{VI})$ within the plume is only around $0.2 \%$, a factor of 3 lower than predicted with conventional $\mathrm{SO}_{x}$ chemistry. An example of the computed profiles for $\mathrm{SO}_{x}$ species in the early plume is provided in Fig. 9.

\section{Sample line modelling}

A large fraction of particles emitted from aircraft engines are volatile and are composed of sulphuric acid, $\mathrm{H}_{2} \mathrm{O}$ and probably low vapour pressure organic compounds. Since such particles can have a significant influence on atmospheric radiation processes, chemical composition and cloud coverage, their formation in aircraft engines and/or aircraft wakes is of great importance. Experimental investigations of trace gas and particulate emission from both combustor and HES required the installation of sampling lines in which the hot air samples are cooled and diluted prior to analysis. Measurements made at the end of sample lines may therefore be affected by processes that modify initial distributions of particles by i.e. nucleation, coagulation and/or hygroscopic growth. Therefore it was deemed important in PartEmis to test such effects by appropriate modelling studies.
The modelled evolution of volatile particles along the sampling line is shown in Fig. 10. As can be seen from this figure the number concentration remains small as long as the temperature is above $450 \mathrm{~K}$. However, upon dilution and cooling of the sample line a rapid increase in number concentrations is noted. This increase depends on FSC, in agreement with experimental measurements during PartEmis. As a result of scavenging of volatile particles, soot particles will be coated with sulphuric acid/ $\mathrm{H}_{2} \mathrm{O}$ during their passage through the sampling line. Under high humidity conditions such particles will absorb water and grow in size as discussed earlier. Hygroscopic growth factors depend on particle size and FSC with the growth being more rapid for smaller particle sizes and higher FSC.

Particle coagulation during sampling was also investigated by using a Brownian motion model in the continuum regime. Model results indicate that for typical number concentrations and frequency factors, coagulation does not affect particle number concentration on a $0.1 \mathrm{~s}$ time scale as appropriate for sampling line conditions during PartEmis [9].

\section{Chemical kinetics database}

The chemical kinetics database needed for box model and/or coupled chemical dynamical codes has been updated with respect to new measurements and calculations of rate coefficients and thermodynamic properties. Since the 


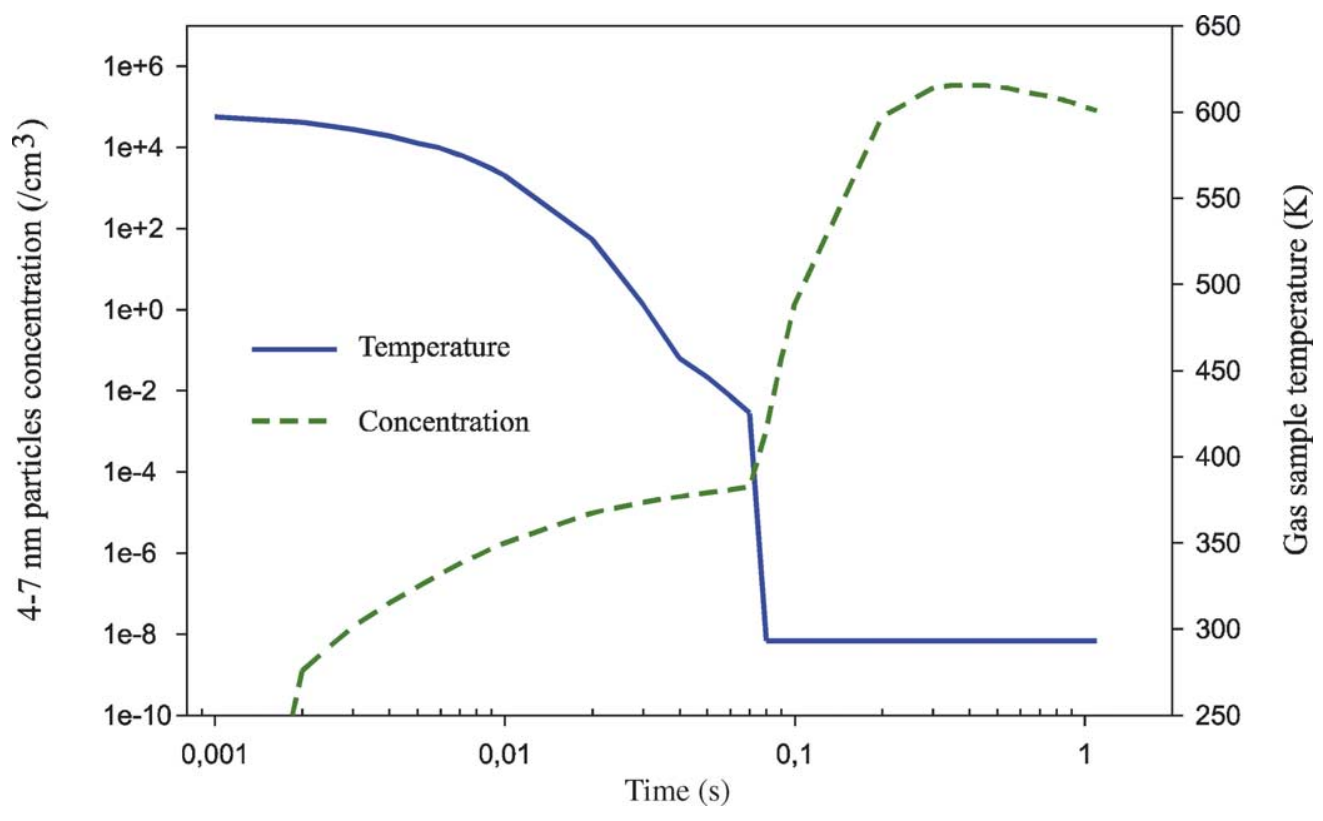

Fig. 10. Calculated evolution of volatile particle concentration in the sampling line during the HES campaign. (Modified after [40].)

$\mathrm{SO}_{x}$ mechanism, which is responsible for the oxidation of $\mathrm{S}(\mathrm{IV})$ to $\mathrm{S}(\mathrm{VI})$ and hence the formation of particulate precursors, is subject to much greater uncertainty than other components of the oxidation mechanism (i.e. $\mathrm{CH}_{4}$ or $\mathrm{NO}_{x}$ mechanisms) special emphasis was placed on improving this aspect. New data for the kinetics of the recombination reaction $\mathrm{OH}+\mathrm{SO}_{2} \rightarrow \mathrm{HOSO}_{2}$ indicate that $\mathrm{HOSO}_{2}$ is considerably less stable than previously assumed [36]. As a result, considerably smaller conversions of S(IV) to S(VI) in aircraft plumes are predicted [37] in agreement with experimental observations both from PartEmis and in-flight studies.

\section{Discussion and conclusions}

The representativity of PartEmis Combustor measurements is illustrated in Fig. 11, which shows black carbon emission indices $\left(\mathrm{EI}_{\mathrm{BC}}\right)$ for various commercial jet engines at cruise altitude from in-flight studies [29,34]. The types of engine have been arranged on the $y$-axis according to $\mathrm{EI}_{\mathrm{BC}}$ values and generally decrease from top to bottom. Emission indices for PartEmis old and modern cruise conditions are close to mean values for the illustrated gas turbine engines. The uncertainty in the emission values was estimated at less than $10 \%$.

Preliminary results from the PartEmis Combustor and HES test campaigns and associated modelling studies suggest that:

(i) The combustor behaves like a typical aircraft engine combustor with respect to thermodynamic data and main emissions. It may thus be expected that the PartEmis database can be applied, to give a first order approximation, to contemporary aircraft engines. (ii) The $\mathrm{BC}$ concentration is nearly independent of FSC level, and no major differences were observed with the APA101 Additive. A possible reason is that the Additive may have a less beneficial effect on high quality fuels (i.e. low aromatic and sulphur concentrations), such as those used during PartEmis.

(iii) Gaseous S(VI) was measured in the form of sulphuric acid. Increased FSC resulted in higher S(VI) concentrations. The measured conversion efficiency $\varepsilon$ for fuel sulphur to S(IV) increased with increasing fuel flow and increasing exhaust age up to $2.3 \pm 1.2 \%$. These values are similar to those measured by MPIK-Heidelberg during an in-flight study (SULFUR 1-7 campaign) which yielded $3.3 \pm 1.8 \%$ [34]. Modelling of sulphur conversion in the combustor, the HES

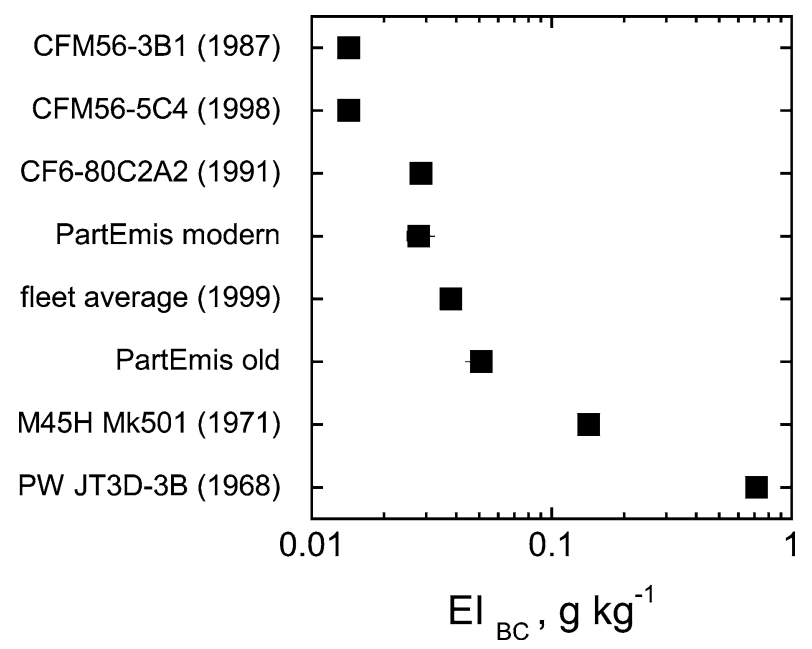

Fig. 11. Black carbon $\left(\mathrm{EI}_{\mathrm{BC}}\right)$ emission indices for various commercial jet engines at cruise conditions. PartEmis old and modern cruise conditions at mid FSC (OMN and MMN, respectively) are shown. Year of engine certification given in brackets. 
and the plume suggests that the major fraction of the conversion occurs in the combustor. The contributions from the HES and/or plume are relatively minor.

(iv) The number size distribution of primary particles in the diameter range $10<d<550 \mathrm{~nm}$ is almost uninfluenced by the FSC level or combustor conditions. But at high FSC levels the formation of new particles with diameters $d<$ $10 \mathrm{~nm}$ by homogeneous nucleation was observed. Modelling of sample line effects indicates that the number distribution of primary particles is not influenced by coagulational losses. Moreover the formation of new particles is found to be induced only after cooling of the sample line.

(v) There is an enhancement in $\mathrm{H}_{2} \mathrm{SO}_{4}$ concentration, particle hygroscopicity, volatility, and $\mathrm{CCN}$ concentration with increasing FSC level.

(vi) More than 100 NMVOCs (aliphatic and aromatic hydrocarbons, carbonyls and acids) were found and quantified. $\mathrm{HC}$ emissions decreased with increasing combustor power at the same FSC. In addition, there was no clear influence of FSC on HC emissions at the same combustor power.

(vii) Positive and negative gaseous ions were detected for the first time in the exhaust of a combustor, with mass numbers up to 1500 . The total ion emission index at the HES hp stage was as high as $1.6 \times 10^{16}$ positive and negative ions per $\mathrm{kg}$ fuel burnt. Large ions with mass numbers exceeding 4500 were also detected, and contributed about $10 \%$ to the total ion number concentration.

(viii) The efficiency of sulphur conversion in the engine has been confirmed by chemical-dynamical modelling as well as from direct measurements to be around $2-3 \%$ with the major contribution arising from the combustor. The additional conversion in the turbine as well as in the plume is of minor importance.

(ix) Formation of volatile particles in jet engine emissions has been demonstrated from microphysical modelling to be the result of cooling and dilution of exhaust gases.

This overview of the EU PartEmis project presents the first comprehensive aerosol and gas measurements to be conducted on a jet engine combustor test-rig. The large database will be used for further in-depth analyses as well as for plume modelling studies.

\section{Acknowledgements}

We gratefully acknowledge the following co-authors who also participated in the formulation of this paper, and towards initiating, conducting and completing PartEmis experiments: F. Arnold, U. Baltensperger, A. Clague, A. Döpelheuer, R. Dunker, M. Fiebig, L. Fritzsche, J.A.G. Gomes, H. Giebl, M. Gysel, H. Haverkamp, R. Hitzenberger, K.J. Hughes, C. Hurley, M. Johnson, M. Kapernaum, E. Katragkou, A. Kiendler, R. Kurtenbach, D.S. Lee, J.C. Lörzer, P. Madden, R. Marsh, Stephan Nyeki, M. Petrea, M. Pourkashanian, H. Puxbaum, C. Stein, S. Vrchoticky, C. Wahl, E. Weingartner, P. Wiesen, S. Wilhelm. The
PartEmis project is funded by the European Commission and by the Swiss Bundesamt für Bildung und Wissenschaft under contract nos. G4RD-CT-2000-00207 and 99.0632, respectively. The assistance of the QinetiQ test-rig crew is highly appreciated.

\section{References}

[1] F. Arnold, H. Haverkamp, A. Sorokin, S. Wilhelm, Electrically charged small positive and negative soot particles in jet aircraft combustor exhaust: First measurements of concentrations and sizes et al., 2003, in preparation.

[2] U. Baltensperger, E. Weingartner, H. Burtscher, J. Keskinen, Dynamic mass and surface area measurements, in: P.A. Baron, K. Willeke (Eds.), Aerosol Measurement, Wiley, New York, 2001, pp. 387-418.

[3] K. Beier, F. Schreier, Modelling of aircraft exhaust emissions and infrared spectra for remote measurements of NO, DLR Report, 1992.

[4] T.C. Bond, T.L. Anderson, D. Campbell, Calibration and intercomparison of filter-based measurements of visible light absorption by aerosols, Aerosol Sci. Technol. 30 (1999) 582-600.

[5] O. Boucher, Air traffic may increase cirrus cloudiness, Nature 397 (1999) 30-31.

[6] CHEMICON "Chemistry and Microphysics of Contrail Formation" ENV4-CT97-0620, Final Report 2000 (R. Zellner, coordinator) available from reinhard.zellner@uni-essen.de.

[7] R.V. Cottington (Ed)., Measurement of trace species in the exhaust of Aero Engines (AEROTRACE), Report no. DERA/AS/PTD/ TR980252/1.0, DERA, Farnborough, UK, 1998.

[8] H. Giebl, A. Berner, G. Reischl, H. Puxbaum, A. Kasper-Giebl, R. Hitzenberger, CCN activation of oxalic and malonic acid test aerosols with the University of Vienna cloud condensation nuclei counter, J. Aerosol Sci. 33 (2002) 1623-1634.

[9] G. Gleitsmann, R. Zellner, Coagulation modelling of sampling line effects during PartEmis, submitted for publication.

[10] G. Gleitsmann, R. Zellner, The effect of ambient temperature and relative humidity on particle formation in the jet regime of commercial aircraft. A modelling study, Atmos. Environ. 18 (1998) 3079-3087.

[11] G. Gleitsmann, R. Zellner, A modelling study of the formation of cloud condensation nuclei in the jet regime of aircraft plumes, J. Geophys. Res. D 16 (1998) 19543-19555.

[12] M. Gysel, S. Nyeki, E. Weingartner, U. Baltensperger, H. Giebl, R. Hitzenberger, A. Petzold, C.W. Wilson, Properties of jet engine combustor particles during the PartEmis experiment. Hygroscopicity at subsaturated conditions, Geophys. Res. Lett. 30 (2003) 1566-1569.

[13] T.L. Hafkenscheid, J.A. van Oosten, Results from inter-laboratory comparisons of aldehyde-2,4 dinitrophenylhydrazone analysis, Anal. Bioanal. Chem. 372 (2002) 658-663.

[14] H. Haverkamp, S. Wilhelm, A. Sorokin, F. Arnold, Positive and negative ion measurements in jet aircraft engine exhaust: Concentrations, sizes and implications for aerosol formation et al., 2003, in preparation.

[15] S.P. Heneghan, S. Zabarnick, D.R. Ballal, W.E. Harrison, JP-8+100: the development of high-thermal-stability jet fuel, J. Energ. Resour.ASME 118 (1996) 170-179.

[16] R. Hitzenberger, H. Puxbaum, Comparisons of the measured and calculated specific absorption coefficients for urban aerosol samples in Vienna, Aerosol Sci. Tech. 18 (1993) 323-345.

[17] R. Hitzenberger, H. Giebl, A. Petzold, M. Gysel, S. Nyeki, U. Baltensperger, C.W. Wilson, Properties of jet engine combustor particles during the PartEmis experiment. Hygroscopic properties at supersaturated conditions, Geophys. Res. Lett. 30 (2003) 1779-1782.

[18] E. Katragkou, S. Wilhelm, A. Kiendler, F. Arnold, C.W. Wilson, Sulfur (VI) in the simulated internal flow of an aircraft gas turbine engine: First measurements, Geophys. Res. Lett. (2003), in press. 
[19] R.J. Kee, J.F. Grcar, M.D. Smooke, J.A. Miller, A fortran program for modelling steady laminar one-dimensional premixed flames, Sandia National Laboratories Report No. SAND85-8240, 1985.

[20] R.J. Kee, F.M. Rupley, J.A. Miller, Chemkin-II. A fortran chemical kinetics package for the analysis of gas phase chemical kinetics, Sandia National Laboratories Report No. SAND89-8009B, 1991.

[21] R. Kurtenbach, R. Ackermann, K.H. Becker, A. Geyer, J.A.G. Gomes, J.C. Lörzer, U. Platt, P. Wiesen, Verification of the contribution of vehicular traffic to the total NMVOC emissions in Germany and the importance of the $\mathrm{NO}_{3}$ chemistry in the city air, J. Atmos. Chem. 42 (2003) 395-411.

[22] R. Kurtenbach, A. Döpelheuer, H. Geiger, J. Heland, R. Kleffmann, M.J. Kapernaum J.C. Lörzer, C. Wahl, P. Wiesen, Measurement of trace species in the exhaust of aero engines, 2003, in preparation.

[23] R. Kurtenbach, A. Döpelheuer, J.A.G. Gomes, M. Kapernaum, J.C. Lörzer, M. Petrea, C. Wahl, P. Wiesen, NMVOC emission of a jet engine combustor during PartEmis, 2003, in preparation.

[24] D.S. Liscinsky, M.B. Colket, D.J. Hautman, B. True, Effect of fuel additives on particle formation in gas turbine combustors, in: 37th Joint Propulsion Conference, 2001, Paper No. AIAA 2001-3745.

[25] R. Marsh, C. Hurley, DERA's measurements on the PartEmis combustor, Report Nos: DERA/FST/CAT/WP010154, unclassified, QINETIQ (formerly DERA), Farnborough, UK.

[26] P. Minnis, D.F. Young, D.P. Garber, L. Nguyen, W.L. Smith, R. Palikonda, Transformation of contrails into cirrus during SUCCESS, Geophys. Res. Lett. 25 (1998) 1157-1160.

[27] S. Nyeki, M. Gysel, U. Baltensperger, R. Hitzenberger, A. Petzold, E. Weingartner, Size spectra and volatile properties of jet engine combustor particles during the PartEmis test-rig experiment, Geophys. Res. Lett. (2003), submitted for publication.

[28] J. Penner, D.H. Lister, D.J. Griggs, D.J. Dokken, M. McFarland (Eds.), Aviation and the Global Atmosphere, IPCC Report, Cambridge, 1999.

[29] A. Petzold, A. Döpelheuer, C.A. Brock, F.P. Schröder, In situ observations and model calculations of black carbon emission by aircraft at cruise altitude, J. Geophys. Res. 104 (1999) 22171-22181.

[30] A. Petzold, C. Stein, S. Nyeki, M. Gysel, E. Weingartner, U. Baltensperger, H. Giebl, R. Hitzenberger, A. Döpelheuer, S. Vrchoticky, H. Puxbaum, M. Johnson, C.D. Hurley, R. Marsh, C.W. Wilson, Properties of jet engine combustor particles during the PartEmis experiment. Microphysical and chemical properties, Geophys. Res. Lett. 30 (2003) 1719-1722.
[31] SAE, ARP1179, Aircraft gas turbine exhaust measurements, Society Automotive Engineers, Rev. C (1997).

[32] U. Schumann, The impact of nitrogen oxides emissions from aircraft upon the atmosphere at flight altitudes - Results from the AERONOX project, Atmos. Environ. 31 (1997) 1723-1733.

[33] U. Schumann, G.T. Amanatidis (Eds.), Aviation, aerosols, contrails and cirrus clouds (A2C3), Air Pollution Research Report 74, European Community, Brussels, 2001.

[34] U. Schumann, F. Arnold, R. Busen, J. Curtius, B. Kärcher, A. Kiendler, A. Petzold, H. Schlager, F. Schröder, K.-H. Wohlfrom, Influence of fuel sulfur on the composition of aircraft exhaust plumes: The experiments SULFUR 1-7, J. Geophys. Res. 107 (2002) AAC 2-1AAC 2-27.

[35] U. Schumann, H. Schlager, F. Arnold, J. Ovarlez, H. Kelder, O. Hov, G. Hayman, I.S.A. Isaksen, J. Staehelin, P.D. Whitefield, Pollution from aircraft emissions in the North Atlantic flight corridor: Overview on the POLINAT projects, J. Geophys. Res. 105 (2000) 3605-3631.

[36] H. Somnitz, R. Zellner, A quantum chemical-dynamical calculation of the rate coefficient for the reaction $\mathrm{OH}+\mathrm{SO}_{2} \rightarrow \mathrm{HOSO}_{2}, 2003$, submitted for publication.

[37] H. Somnitz, G. Gleitsmann, R. Zellner, Theory based rate coefficients from the reaction $\mathrm{OH}+\mathrm{SO} \rightarrow \mathrm{HOSO}_{2}$ overall extended range of pressure and temperature: Model description and implications for aircraft plume chemistry, in: G.D. Ray, et al. (Eds.), Combustion and Atmospheric Pollution, Torus Press, Moscow, 2003.

[38] A.M. Starik, A.M. Savel'ev, N.S. Titova, U. Schumann, Modeling of sulfur gases and chemiions in aircraft engines, Aerosp. Sci. Techn. 6 (2002) 63-81.

[39] J. Ström, S. Ohlsson, In situ measurements of enhanced crystal number densities in cirrus clouds caused by aircraft exhaust, J. Geophys. Res. 103 (1998) 11355-11361.

[40] H.G. Tremmel, U. Schumann, Model simulations of fuel sulfur conversion efficiencies in an aircraft engine: Dependence on reaction rate constants, Aerosp. Sci. Technol. 3 (1999) 417-430.

[41] X. Vancassel, A. Sorokin, P. Mirabel, Volatile particles formation during PartEmis. A modelling study, 2003, submitted for publication.

[42] J. Wolfrum, Advanced laser spectroscopy in combustion chemistry: From elementary steps to practical devices, Faraday Discuss. 119 (2001) 1-26. 